\title{
INDÚSTRIAS CRIATIVAS: REFLEXÕES À LUZ DA MICROECONOMIA
}

\section{CREATIVE INDUSTRIES: MICROECONOMIC REFLEXIONS}

\section{Alexandre Sette Abrantes Fioravante}

Doutor em Desenvolvimento Econômico pela Universidade Estadual de Campinas (Campinas/Brasil).

Professor do Centro Universitário SENAC São Paulo (São Paulo/Brasil).

E-mail: alexandresettefioravante2@gmail.com.

\section{Magnus Luiz Emmendoerfer}

Pós-doutor em Administração Pública pela Universidade do Minho.

Professor Associado no Departamento de Administração

e Contabilidade da Universidade Federal de Viçosa.

E-mail: magnus@ufv.br. 


\section{RESUMO}

O significativo processo de evolução da dinâmica dos padrões de comunicação, trazidos no contexto de surgimento do paradigma das tecnologias da informação e comunicação (TICs), das relações culturais, sociais e ambientais, que têm afetado nas últimas décadas setores fundamentais da economia global, evidencia o deslocamento do foco das atividades industriais para atividades intensivas em conhecimento e criatividade, localizadas no setor de serviços. 0 objetivo deste estudo teórico é analisar as indústrias criativas à luz de conceitos da área de microeconomia, tendo como contexto o paradigma das TICs e um novo formato de indústrias, que apresentam padrão de concorrência, tendo como base recursos intangíveis. Ao longo das discussões teóricas aqui apresentadas, procurou-se introduzir também conceitos microeconômicos para a reflexão deste setor, que apresenta uma nova classe de trabalhadores, especificamente centrando nas questões de análise da rivalidade e interdependência no campo das indústrias criativas e de barreiras à entrada nos mercados criativos. Em termos metodológicos, adotou-se um ensaio teórico com abordagem qualitativa tendo como base o método bibliográfico. Através deste, foi possivel realizar o levantamento de informações em livros, artigos científicos e sites especializados sobre o tema tratado. Enquanto contribuição, este estudo possibilita a aproximação da microeconomia, resgatando discussões microeconômicas clássicas, à temática das indústrias criativas, um tema relativamente novo no cenário brasileiro, sendo necessário o desenvolvimento de estudos microeconômicos voltados para as indústrias criativas no intuito de aprofundar a dinâmica destes mercados que introduzem novo padrão de concorrência.

Palavras-chave: Indústrias criativas. Microeconomia. Tecnologias da Informação e Comunicação.

\section{ABSTRACT}

The communication patterns dynamics has been going under a significant process of evolution, brought in the context of the emergence of the paradigm of information and communication technologies (ICTS), and associated to the changes in the cultural, social and environmental relations. Such considerable changes that have affected in the last decades fundamental sectors of the global economy shows the displacement from the focus of industrial activities to the intensive activities in knowledge and creativity, located mainly in the services sector. In this context, the objective of this study is to make a theoretical effort to integrate the analysis of the creative industries to some concepts of the microeconomics area, having as a prior base the paradigm of ICTs and a new format of industries that present a standard of competition, which is based over the intangible resources. Throughout the theoretical discussions presented here, it was also tried to introduce microeconomic concepts for the reflection of this creative economy sector, which presents a new class of workers, specifically focusing on the issues of analysis of rivalry and interdependence in the field of creative industries, and barriers to entry creative markets. In methodological terms a theoretical essay with qualitative approach was adopted, based on the bibliographical method. Through this it was possible to carry out the collection of information in books, scientific articles and specialized websites on the theme discussed here. As contributions, it is possible to point that this study brings microeconomics, rescuing the classic macroeconomic discussions, closer to the theme of the creative industries, which is a relatively new topic, specifically in the Brazilian scenario, and it is necessary to develop microeconomic studies aimed at the creative industries, in order to dynamism of these markets which introduce a new pattern of competition.

Keywords: Creative indústries. Microeconomics. Information and Communication Technologies. 


\section{INTRODUÇÃo}

O significativo processo de evolução da dinâmica dos padrões de comunicação, trazidos no contexto de surgimento do paradigma das tecnologias da informação e comunicação (TICs) e das mudanças nas relações culturais, sociais e ambientais, que têm afetado nas últimas décadas setores fundamentais da economia global, evidencia o deslocamento do foco das atividades industriais tradicionais para as atividades intensivas em conhecimento e criatividade, localizadas no setor de serviços.

No bojo destas transformações, evidencia-se o surgimento de uma "nova economia1", segundo Florida (2011), conduzida pela criatividade e pela ascensão de uma nova "classe criativa". Para o referido autor, existe a necessidade da atração e retenção de uma classe de profissionais criativos para o sucesso e desenvolvimento de territórios (ASHTON, 2019). Isto porque esta nova classe é capaz de trazer transformações nas relações do lado produtivo e socioeconômico dos países, principalmente nos mais desenvolvidos e, neste contexto, dever-se-ia pensar na "nova economia" como sendo construída em torno das "indústrias criativas" (HOWKINS, 2001).

Sobre as discussões em torno das relações entre criatividade e desenvolvimento de territórios, cabe ressaltar, segundo Ashton (2019), o papel das grandes transformações observadas em nível mundial, a saber: globalização; tecnologias de informação; aumento significativo da população em cidades; e redução da sustentabilidade nos grandes centros urbanos. Estes fatores passaram a demandar novas necessidades e novas urgências, entre elas a busca por novos caminhos visando acelerar o desenvolvimento baseado em um novo modelo de organização no território, para que se possa manter a competitividade econômica de cidades e regiões. Vale destacar a urgência de inovar na produção de bens e serviços, ou seja, a necessidade de novos produtos e novos processos (ASHTON, 2019).

Nesse caminho, a economia criativa tem se mostrado estratégica para promover o desenvolvimento e crescimento, como tem sido indicado em planos governamentais (EMMENDOERFER; FIORAVANTE; ARAÚJO, 2018). É um setor que trabalha com ativos intangíveis, onde os recursos se renovam e multiplicam com o uso (POSSAS, 1997), sendo, portanto, uma atividade de forte desempenho econômico, mas também de interação social, ambientalmente correta e que fortalece os valores diferenciais e a credibilidade de comunidades e empresas.

\footnotetext{
${ }^{1} \mathrm{O}$ autor usa este termo para introduzir uma economia caracterizada pela abundância e não pela escassez. A nova economia possui dinâmica própria e, por isso, acaba fugindo dos modelos econômicos tradicionais, pois seus novos modelos de negócio ainda se encontram em construção, carecendo de marcos legais e de bases conceituais consentâneas com os novos tempos.
} 
Assim, conhecimento e criatividade podem ser vistos como importantes fatores de produção. Possas (1997) aborda como o conhecimento e a criatividade entrariam na atividade econômica. $\mathrm{O}$ que a autora propõe é que, além dos fatores de produção tradicionais como terra, trabalho e capital, temos o conhecimento e a criatividade como fator de produção. As indústrias criativas podem ser vistas como um novo e potencial campo econômico. Seu potencial de crescimento e sua contribuição na geração de renda dos países e na composição do emprego vêm sendo atestados em diversos estudos, governamentais e acadêmicos, ao redor do mundo nas últimas décadas.

As indústrias criativas referem-se à convergência de três campos anteriormente mantidos separados: artes, indústrias culturais e novas tecnologias digitais de informação. Resultados apontados pelo relatório da Organização das Nações Unidas para Educação, Ciência e Cultura - UNESCO (2007) revelam que, desde a última década do Século XX, pequenas e médias empresas pertencentes ao segmento das indústrias criativas desempenham importante papel na economia dos países avançados, atuando principalmente como força motriz para o crescimento econômico e desenvolvimento social.

Em decorrência, observa-se uma tendência favorável à formatação de um novo perfil de atividades econômicas, cada vez menos voltado ao tradicional modelo industrial e atividades urbanas convencionais, como o comércio, e mais relacionado à geração de ideias e à exploração do talento e da criatividade humana de um determinado contexto (ASHTON, 2019) ou organização (VIEIRA, 1998). Trata-se de um conjunto de indústrias que concentram altos gastos em atividades de $P \& D$, no intuito de identificar suas competências essenciais e incorporá-las para definir suas estratégias corporativas (PRAHALAD; HAMEL, 1998). São indústrias com base em ativos inflexíveis (POSSAS, 1995), que pelo seu baixo grau de apropriabilidade por parte das firmas rivais conferem um importante diferencial de concorrência. Inserido nestas discussões, o objetivo deste estudo é realizar um esforço teórico de integrar a análise das indústrias criativas a alguns conceitos da área de microeconomia, tendo como contexto o paradigma das TICs e um novo formato de indústrias, que apresentam um padrão de concorrência, baseado em recursos intangíveis. Este esforço teórico se justifica pela necessidade de trazer mais robustez e respaldo para as discussões sobre indústrias criativas, em especial no contexto brasileiro. 


\section{PROCEDIMENTOS METODOLÓGICOS}

Em sintonia com o objetivo deste estudo e as posições teóricas que serão trabalhadas a seguir, adotou-se uma abordagem qualitativa para este ensaio teórico (BURGOON, 2001). Este ensaio segue orientação epistemológica de natureza interpretativa, a fim de provocar reflexões no decorrer da exposição sobre o objeto em estudo. Seus referenciais analíticos têm predominantemente como base trabalhos que abordam questões a serem analisadas sob uma perspectiva econômica.

Este ensaio tem sua base no método bibliográfico, por meio de fontes indicadas na seção de referências desse estudo. Assim, foi possivel realizar o levantamento de informações em livros e artigos científicos nos temas sobre as abordagens de microeconomia, criatividade, indústrias criativas, análise da rivalidade e interdependência no campo das indústrias criativas e de barreiras à entrada nos mercados criativos.

Segundo Gil (2006), o método bibliográfico tem a finalidade de fazer com que o pesquisador entre em contato direto com todo o material escrito sobre um determinado assunto, auxiliando na análise de suas pesquisas ou na manipulação de suas informações. Este estudo pode ser classificado, segundo Gil (2006) e Vieira (2004), como exploratório, uma vez que procurou proporcionar maior familiaridade com o tema no intuito de torná-lo mais explícito e, ainda, na tentativa de aprimorar as ideias e propor premissas para análise entre a aplicação das abordagens microeconômicas, a fim de analisar aspectos de concorrência e barreiras à entrada no contexto dos novos modelos de negócio praticados nas indústrias criativas.

Os dados e as informações levantadas foram então cotejados, importante prática de pesquisa para extrair e articular o que foi obtido nas bibliografias desta pesquisa. É importante destacar que, durante a fase de pesquisa bibliográfica, constatou-se a escassez de trabalhos acadêmicos e práticos especificamente sobre o olhar da microeconomia em torno do tema das indústrias criativas, sinalizando para a necessidade de mais estudos acadêmicos como este.

Este estudo foi estruturado em quatro seções de análise e discussão de dados, além das considerações finais. A primeira seção trata de aspectos gerais sobre a economia criativa e o contexto de surgimento das indústrias criativas. Na sequência, articula-se o processo de análises teóricas e aplicação das abordagens microeconômicas ao tema das indústrias criativas. Nesta segunda seção, procurou-se também inserir conceitos microeconômicos para a reflexão deste setor, especificamente centrando nas questões de Análise da Rivalidade e interdependência no campo das indústrias criativas. A quarta seção discute as barreiras à entrada nos mercados criativos: o papel do conhecimento enquanto ativo inflexivel. 


\section{REVISITANDO OS CONCEITOS DE ECONOMIA CRIATIVA E INDÚSTRIAS CRIATIVAS: REFLEXÕES À LUZ DA MICROECONOMIA}

Em sua obra "A Ascensão da Classe Criativa", Florida (2011) enxerga a economia atual em sua essência como uma economia criativa. Segundo este autor, Peter Drucker esboçou bem os contornos da nova economia ao baseá-la no conhecimento e apontar que os meios de produção básicos, como capital, trabalho e recursos naturais, perderiam espaço para um novo recurso econômico essencial: o conhecimento (DRUCKER, 2002). Mas, para Florida, a criatividade - criação de novas práticas a partir desse conhecimento - seria de fato a principal força propulsora, pois conhecimento e informação são ferramentas e materiais para a criatividade (FLORIDA, 2011).

A dedicação a atividades criativas não deve ser vista como novidade, desde a antiguidade as pessoas já se dedicavam a atividades criativas. O que difere uma época da outra é que na atualidade estas atividades estão se tornando predominantes, prova disto seriam as estruturas econômicas criadas em torno destas como formas de suporte. Apropriando-se das ideias clássicas de Hirschman (1961) sobre os efeitos de encadeamento, poder-se-ia dizer que atividades criativas possuem um grande poder de encadeamento "para traz" e "para frente", ou seja, tem condição ou capacidade de ser responsável pela indução de novas atividades e de procura, levando ao surgimento de outros setores mais recentes.

A economia criativa representa, para Reis (2008), o emblema de um novo ciclo econômico, que surge como resposta a problemas globais renitentes. Esse novo paradigma tem a tecnologia como veículo propulsor, a organização dos mercados em redes, as parcerias entre os agentes sociais e econômicos, a prevalência de aspectos intangíveis da produção, o uso das novas tecnologias para a produção, distribuição e/ou acesso aos bens e serviços e a unicidade da produção fortemente ancorada na singularidade, o que confere um diferencial em termos de competitividade para as empresas deste setor.

Quando o termo "indústrias criativas" foi cunhado, no final dos anos de 1990, primeiramente na Austrália, ganhando em seguida impulso na Inglaterra, soou como uma oportunidade para discutir as questões econômicas dentro de uma ampla gama de setores diversos, porém conectados. Vários autores conceituam o termo indústrias criativas, como Caves (2000), Florida (2011), Howkins (2005) e Hartley (2005). Pela definição dos autores que trabalham este tema, percebem-se alguns aspectos interessantes, entre estes o de que indústrias criativas têm o elemento criatividade como insumo essencial; nelas a cultura acaba sendo tratada na forma de objetos culturais definidos pela carga de sentidos socialmente compartilhados.

As indústrias criativas compreenderiam, entre outras, às atividades relacionadas a teatro, cinema, publicidade, arquitetura, mercado de artes e de antiguidades, artesanato, design, design de moda, 
softwares interativos para lazer, música, indústria editorial, rádio, TV, museus, galerias e outras atividades vinculadas às tradições culturais (BENDASSOLLI et al. 2009).

Partindo de uma análise da produção bibliográfica a respeito de autores que trabalham o tema economia criativa, Reis (2008) nota que esta era marcada pelo foco em indústrias criativas e sua dinâmica econômica (CAVES, 2000; HOWKINS, 2001) ou nas características e capacitação dos trabalhadores dessas indústrias como exposto por Florida (2011). A profusão de interpretações conceituais não sugere uma linha comum entre as abordagens (REIS, 2008).

Em trabalhos mais recentes, a UNCTAD (2010, p. 22) acabou definindo uma abordagem mais ampla e holística para tratar economia criativa, seguindo uma vertente mais "[...] multidisciplinar, lidando com a interface entre economia, cultura e tecnologia, centrada na predominância de produtos e serviços com conteúdo criativo, valor cultural e objetivos de mercado [...]". Caves (2000), entende por indústrias criativas aquelas relacionadas às artes, cultura e entretenimento em geral. Howkins (2001) vê que o divisor de águas da economia criativa seria o potencial de gerar direitos de propriedade intelectual (segundo o autor, a "moeda da economia criativa"), expandindo sua abrangência dos direitos autorais para desenhos industriais, marcas registradas e patentes (REIS, 2008).

O fenômeno das indústrias criativas é definido por Roodhouse (2008) como um constructo que fornece um quadro de possibilidades de interação entre os setores privado e público. Estudo realizado pelo The Creative Industries Task Force (2008) revela que o conceito de indústrias partiu preliminarmente de um interesse na economia do conhecimento e pragmaticamente acabou definindo que as indústrias criativas envolvem aquelas atividades com origem na criatividade do indivíduo, suas habilidades e talento, tendo um potencial relevante de criação de riqueza e de emprego através da geração da propriedade intelectual.

Desta forma, não se deve enxergar a economia criativa como um apanhado de setores embalados em uma nova categoria, mas o emblema de um novo ciclo econômico, surgindo como resposta a problemas globais consoantes, que motivam e embasam novos modelos de negócios, processos organizacionais e institucionais e relações entre os agentes econômicos e sociais. Nesse novo paradigma - que traz a cultura como base conectada à tecnologia como veículo propulsor -, a organização dos mercados em redes, parcerias entre agentes sociais e econômicos, prevalência de aspectos intangíveis da produção, uso das novas tecnologias para a produção, distribuição e/ou acesso aos bens e serviços e à unicidade da produção, fortemente ancorada na singularidade, são traços característicos de um modelo que apresenta como pressuposto de sustentabilidade a melhoria do bem-estar e a inclusão socioeconômica (REIS, 2008).

Assim, para uma análise das indústrias criativas à luz da microeconomia, foram resgatadas ideias propostas por importantes autores como Silva Possas (1997; 1995) que tratou da tipologia de ativos, 
situando a importância que o conhecimento, enquanto ativo inflexível, tem para conferir competitividade às empresas (POSSAS, 1995), bem como das principais características do conhecimento e suas implicações econômicas (POSSAS, 1997). Resgataram-se também as proposições de Prahalad e Hamel (1998), quanto à relevância das competências essenciais para as estratégias das empresas. Essa reflexão também tem como pano de fundo as discussões de Tigre (2005), sobre os paradigmas tecno-econômicos, e de Chesnais (1994). Este último é importante para situar as indústrias criativas dentro da discussão da questão da coordenação crescente de capital e o formato de operações descentralizadas das empresas rede. Este formato descentralizado é característico das grandes empresas criativas inseridas no complexo da indústria criativa.

\section{ANÁLISE DA RIVALIDADE E INTERDEPENDÊNCIA NO CONTEXTO DAS INDÚSTRIAS CRIATIVAS}

Modelos microeconômicos tradicionais propõem uma ideia de concorrência perfeita pautada pela ausência de assimetria de informações, pois estas estariam disponíveis sem custos, o perfeito funcionamento do mercado. Estas hipóteses parecem se distanciar bastante da realidade do contexto das indústrias criativas.

Estudos sobre indústrias criativas (NEF, 2002; UNCTAD, 2010) revelam que sua competitividade está, justamente, nas diferentes estratégias para atuar no mercado (conduta): diferenciação do produto, alto investimento em design para produtos singulares, investimentos elevados em $P \& D$, propaganda e marketing, entre outros.

Nessa discussão, cabe ressaltar o que Possas (1997) apontou. Para a autora, conhecimento é o principal elemento diferenciador da concorrência por gerar vantagem competitiva para a firma, tendo em vista, principalmente, assimetrias geradas a partir de sua dimensão tácita, que uma vez se acumulando no tempo vai somente reforçar o poder da firma no processo de concorrência. Esse movimento tem explicação também no fato de que tudo isso colabora para que estas indústrias tenham uma arquitetura que sinalize para as suas competências estratégicas² (PRAHALAD; HAMEL, 1998).

\footnotetext{
${ }^{2}$ A importância das competências essenciais para a corporação, segundo Prahalad e Hamel (1998), se liga às estratégias corporativas. Tais competências essenciais são, de fato, a fonte geradora de desenvolvimento de novos negócios e, portanto, devem construir o foco para a estratégia em nível corporativo. De acordo com os autores, as competências essenciais são o aprendizado coletivo na organização, especialmente como coordenar as diversas habilidades de produção e integrar as múltiplas correntes de tecnologias. Elas se ligam à harmonização de correntes de tecnologias, mas também estão associadas à organização do trabalho e à entrega de valor.
} 
Estas indústriastêm sua centralidade nos recursos imateriais, intangíveis e renováveis. Conhecimento e criatividade são infinitos, elásticos. São recursos que não apenas não se esgotam como se renovam e multiplicam com o uso (POSSAS, 1997). Trabalhar com estratégias de crescimento e inovação a partir de recursos intangíveis e de novos modelos de gestão, apesar de ser uma tarefa difícil, tem muito a contribuir em termos de ganhos de competitividade, tanto quando a análise é feita em um contexto mais macro, quanto em um contexto micro, neste último, olhando especificamente para as empresas.

As evidências atuais comprovam que as tecnologias digitais e os serviços das TICs estão simulando a criação e a comercialização de produtos criativos digitalizados por meio de novos modelos de negócio, e que essa convergência e digitalização estão ajudando os produtos criativos de países em desenvolvimento a alcançar mercados globais.

De fato, a criatividade - ou, digamos, a capacidade de inovar de forma significativa - se consolidou como fator determinante da vantagem competitiva das empresas. Como observado por Florida (2001), em praticamente todos os segmentos da economia, aqueles que conseguem criar e continuar inovando são os que obtêm sucesso de longo prazo.

Na verdade, desde a primeira revolução industrial até a terceira (TIGRE, 2005), sempre foi assim. A diferença é que nas últimas décadas as empresas passaram a reconhecer a importância da criatividade e da inovação no seu planejamento estratégico, a importância de atuar no "formato rede" em termos de ganhos com custos mais baixos e agilidade dos serviços (CHESNAIS, 1994).

Ainda, é necessário reconhecer a existência de uma interdependência entre as ações das empresas criativas, um mercado altamente interligado, onde as ações individuais têm efeito direto sobre as outras concorrentes (MASON, 1939; BAIN, 1956; LABINI, 1956), principalmente considerando os avanços das tecnologias da informação e comunicação. Na abordagem neoclássica de concorrência perfeita, a ação de uma firma é tomada como independente, não influenciando o todo.

A abordagem imposta pelas indústrias criativas esboça que estas "[...] indústrias que tiveram origem na criatividade, habilidade e talento individuais e têm um potencial para geração de empregos e riquezas por meio da geração e exploração da propriedade intelectual" (BRITISH COUNCIL, 2005, p. 5, tradução nossa) têm suas vantagens na ausência de perfeita informação. Exemplo disso é visto nas grandes indústrias criativas globais como a Google e a Apple, empresas criativas por excelência.

Nem todo conhecimento e criatividade são totalmente apropriáveis, nem todo o trabalho humano é perfeitamente replicável para qualquer contexto, tampouco as capacidades criativas dos indivíduos são similares. Por tudo isso, não há espaço para pensar em ausência de rivalidade e perfeita simetria de informações no campo das indústrias criativas. Tudo isso ganha proporções maiores pelo fato de estas indústrias usarem as TICs como seu veículo propulsor maior. 


\section{BARREIRAS À ENTRADA NOS MERCADOS CRIATIVOS: O PAPEL DO CONHECIMENTO ENQUANTO ATIVO INFLEXIVEL}

A análise das barreiras à entrada de uma indústria em determinados mercados, com o objetivo de identificar e avaliar os determinantes do seu desempenho, foi originalmente desenvolvida pelos trabalhos de Joe Bain e Paolo Sylos-Labini nos anos 1950. As contribuições teóricas destes autores propiciaram a base sobre a qual foi construído o paradigma Estrutura - Conduta - Desempenho (E-C-D)³. Bain (1956) introduziu a ideia de barreiras à entrada como forma de buscar na estrutura dos mercados a explicação para o desempenho econômico.

Conforme exposto por Silva (2004), com base em Bain (1956), os principais determinantes das barreiras à entrada, extraídos com base na análise da natureza das vantagens que as empresas estabelecidas possuem frente às potenciais rivais, se dariam sob três circunstâncias (apoiadas em fatores tecnológicos e institucionais): vantagens absolutas de custos; vantagem de diferenciação de produtos das empresas estabelecidas e economias de escala.

A vantagem absoluta de custos decorre de fatores como: a entrada de uma empresa fazendo elevar os preços de um ou mais insumos de produção, tanto para as empresas estabelecidas quanto para as empresas entrantes, aumentando os custos; outro fator seria de que as empresas existentes podem possuir acesso privilegiado a recursos produtivos a preços mais reduzidos que aqueles obtidos pela empresa entrante. Por fim, o fato de as firmas estabelecidas poderem ter acesso preferencial a técnicas de produção mais econômicas que a empresa entrante, o que incorre em custos menores.

As vantagens conquistadas a partir de diferenciação de produtos resultam da preferência dos consumidores pelos produtos já existentes quando comparados com os novos. Este tipo de vantagem tem, no entanto, sua efetividade atrelada à importância das economias de escala de produção e venda na indústria. Se não existem economias de escala, o entrante potencial, mesmo diante das preferências dos consumidores pelos produtos que já existem, não sofrerá qualquer desvantagem (embora trabalhe com nível de produção menor).

A presença de economias de escala significa que os custos unitários de produção e distribuição caem com o aumento da produção, e a escala de produção correspondente aos custos unitários mínimos, planta ótima, responde por parcela expressiva da produção. Diante desta situação, as firmas potenciais

\footnotetext{
${ }^{3}$ Nos modelos ECD, busca-se, sinteticamente, derivar de características da estrutura do mercado conclusões acerca do seu desempenho em termos de alguma variável escolhida, supondo, para isso, que as condutas das empresas são fortemente condicionadas pelos parâmetros estruturais vigentes. Para maiores detalhes ver Bain (1956); Sylos-Labini (1956).
} 
entrantes enfrentam o dilema: entrar no mercado em uma escala inferior à mínima eficiente e incorrer em custos mais elevados à operação em níveis de produção relativamente reduzidos, ou buscar operar com custos mínimos associados à produção em escala ótima, mas não tendo a garantia de que possa vir a conseguir, haja visto o ambiente de riscos quando se assume uma escala de produção maior.

É importante introduzir aí o elemento conhecimento e criatividade enquanto fator de barreira à entrada para novas empresas em determinado mercado. Apesar das vantagens que podem estar associadas aos ativos mais flexíveis, como aquelas decorrentes de ganhos de escala e de escopo, estas vantagens tendem a perder parte de sua importância, se não acompanhadas de outras, baseadas em ativos intangiveis. Portanto, a empresa deve procurar aproveitar da melhor maneira possivel seus ativos intangiveis, tendo a noção de que eles são peça-chave da estratégia competitiva da firma, fundamentais para a compreensão da natureza e da dinâmica das firmas (POSSAS, 1995). Ademais, como já mencionado, estes ativos são importantes no processo de construção de uma arquitetura estratégica alicerçada nas competências essenciais das empresas.

De acordo com Possas(1995), pode-se perceber uma tipologia de ativos que estariam divididos em: ativos físicos (podem ser transformados em dinheiro pela venda, mas sempre haverá perda de valor em relação ao que custou); ativos humanos (seria melhor chamar de recursos humanos, que podem ser transferidos, mas também com um nível de perda, principalmente de capacidades/informações, sendo sempre necessário haver algum tipo de treinamento adicional); ativos financeiros (bastante flexíveis, podendo ser facilmente transferidos de um setor para outro); e recursos imateriais (menos flexíveis e englobando imagem, boas relações, experiências e capacidades).

Nas últimas décadas, as empresas não só passaram a reconhecer a importância do conhecimento (ativo inflexível) como insumo de produção como perceberam seu papel transformador no sistema produtivo. Além do capital, da matéria-prima e da mão de obra, as áreas estratégicas das empresas voltaram seus olhos para o uso das ideias como recurso essencial para geração de valor. Na esteira desse movimento, surgiram ao redor do globo modelos de negócios e setores completamente novos, fomentando a geração de empregos e riqueza.

Como proposto por Possas (1997), o conhecimento interfere na concorrência por conferir vantagem competitiva à firma, ele é indispensável para a obtenção de rendimentos que cubram os custos de produção; cria desigualdades, mas também aprofunda estas desigualdades.

O bom desempenho das indústrias criativas evidencia a força destes ativos inflexíveis. Como ressaltado por relatórios internacionais (UNCTAD, 2010), estima-se que tais indústrias tenham agregado à economia mundial um valor de aproximadamente US\$2,2 trilhões, tomando o ano de 1999 como referência. Isso implica em uma participação de 7,5\% do PIB mundial. A estimativa futura de crescimento deste setor é de 10\% ao ano. 
Seu papel como um dos principais segmentos econômicos cresce sucessivamente, de acordo com a UNCTAD (2008), entre 2000 e 2005 o comércio internacional de bens e serviços criativos cresceu à taxa anual de $8,7 \%$. Neste contexto, os setores criativos mostram-se fundamentais para dar competitividade e o diferencial para cidades, países e indústrias.

Sob a ótica da economia criativa, a capacidade de criar do homem é o principal insumo de produção, estando presente não só nas empresas criativas, mas em toda a economia. Com efeito, os profissionais criativos estão distribuídos por todos os setores econômicos, até mesmo nos mais tradicionais. Por exemplo, um designer pode estar empregado em uma siderúrgica ou na indústria automotiva, enquanto os desenvolvedores de sistemas estão presentes em quase todos os setores, embora não trabalhem em uma empresa cuja atividade econômica seja necessariamente criativa.

Um pequeno exemplo, para o caso do Brasil, mostra o alinhamento a essa tendência internacional. Em 2011, 243 mil empresas formavam o núcleo da indústria criativa. Sob uma perspectiva mais abrangente, os números mostram que toda a Cadeia da Indústria Criativa, incluindo atividades relacionadas e de apoio, movimenta mais de 2 milhões de empresas brasileiras.

Com base no volume salarial gerado por essas empresas, estima-se que o núcleo criativo gera um Produto Interno Bruto equivalente a R $\$ 110$ bilhões, ou 2,7\% do total produzido no Brasil. Essa cifra chega a $\mathrm{R} \$ 735$ bilhões se considerada a produção de toda a cadeia da indústria criativa nacional, equivalente a $18 \%$ do PIB brasileiro.

Tendo em vista tudo isso, fica evidente a importância dos ativos inflexíveis enquanto componentes do poder de competitividade das indústrias criativas. Visto como uma barreira à entrada, dado o seu caráter cumulativo, as indústrias criativas tendem a constituir um setor em que as barreiras à entrada são altas, pelo constante alto custo em P\&D. Manter-se na disputa pelos mercados no ambiente criativo exige flexibilidade e que a empresa seja aberta às ondas de inovação do mercado.

\section{CONSIDERAÇÕES FINAIS}

A partir do objetivo traçado neste artigo, que foi analisar as indústrias criativas à luz de conceitos da área de microeconomia, tendo como contexto o paradigma das TICs e um novo formato de indústrias com padrão de concorrência baseado em recursos intangíveis, verificou-se o relevante papel da economia criativa como atividade econômica potencial para os próximos anos. Seu potencial de crescimento recai principalmente no tipo de insumos que formam a base destas indústrias: conhecimento e criatividade.

Resgatando as noções de fonte de vantagens competitivas, temos a diferenciação de produtos (que podem estar acessiveis mesmo para empresas de pequeno porte), as economias de escala, segundo as 
contribuições de Bain (1956) e Sylos-Labini (1956), que são as fontes mais fortes de barreiras à entrada, além das fontes de vantagem competitiva ligadas ao acesso privilegiado a insumos, matérias-primas ou mesmo informações. Neste contexto, pode-se perceber que as TICs exercem um poder de influência em todas estas fontes de vantagens competitivas, seja possibilitando aumento de economias de escala, redução de custos, ou acelerando o processo de diferenciação de produtos e possibilitando o acesso a novos mercados e informações.

No entanto, podemos perceber que as contribuições empreendidas por estes autores têm caráter estático. Quando se tem como contexto um setor altamente intensivo em conhecimento e dinâmico, torna-se necessário agregar outras interpretações.

Silva Possas (1995; 1997) e Prahalad e Hamel (1998) são autores que colaboram para uma análise microeconômica das indústrias criativas, com seus estudos sobre conhecimento e criatividade, e sobre as competências essenciais para as empresas, pontuando como estes fatores são importantes para conferir maior competividade.

Destaca-se, também, a necessidade de novos estudos, inclusive mais aprofundados, sobre a análise dos efeitos dinâmicos dos diferenciais de custos e margens de lucro sobre as estruturas industriais inseridas no contexto da economia criativa, haja vista o caráter dinâmico deste setor. Mesmo assim, a partir da análise inicial proposta por este ensaio, evidencia-se que estas indústrias têm, nos ativos intangíveis, conhecimento e criatividade, a sua maior fonte de competitividade e dinamismo, uma vez que, por serem de caráter inflexível, não são totalmente apropriáveis e permitem a estas empresas acumular know how centrado em suas competências essenciais.

Uma vez que a difusão das tecnologias de informação e comunicação (TICs) aceleraram o processo de codificação do conhecimento e a disseminação de informações, pode-se enxergar a relação entre as TICs e as indústrias criativas como no mínimo complexa. Estas indústrias funcionam dentro de um modelo de mercado que é altamente interligado (papel desempenhado justamente por estas novas tecnologias), onde a capacidade de uso da tecnologia a favor da organização deve ser entendida como ponto chave determinante de sucesso nestes mercados. Isto porque, como já dito por Mason (1939), Bain (1956) e Labini (1956), a ação de uma organização tem efeito direto sobre as suas concorrentes.

Cabe ressaltar que as indústrias criativas apresentam um forte conteúdo de intangíveis, demandando, portanto, habilidades especiais da força trabalho, apresentando estreita relação com os avanços científicos e tecnológicos. Neste sentido, os avanços tecnológicos podem favorecer o desempenho das indústrias criativas a partir de vantagens em termos de custos, desenvolvimento de novos produtos e economias de escala.

Por fim, pelo fato de a temática das indústrias criativas ser tema relativamente novo, especificamente no cenário brasileiro, ressalta-se a necessidade de estudos microeconômicos neste contexto, no intuito de 
aprofundar sobre a dinâmica destes mercados que introduzem novo padrão de concorrência. Esta discussão, apesar de ter suas bases em conceitos mais clássicos da microeconomia, torna-se interdisciplinar, sendo interessante para diferentes áreas do conhecimento que de forma transversal tratam da temática das indústrias criativas, como os estudos organizacionais e sobre formação de novos modelos de negócios inseridos no contexto da administração. É uma discussão preliminar para entender como estes setores baseados em um ativo intangivel podem desenvolver padrões de comportamento e de concorrência. Países em desenvolvimento, como o Brasil, estão lidando recentemente com a temática das indústrias criativas, seja por meio de políticas públicas ou de projetos em parceria com o setor privado, e esta discussão também deve envolver todos os atores interessados no desenvolvimento deste campo de atuação.

\section{REFERÊNCIAS}

ASHTON, M. S. G. Cidades criativas: contexto histórico e conceitual. In: ASHTON, M. S. G (Org.). Cidades criativas: vocação e desenvolvimento. Nova Hamburgo: Feevale, 2018. Disponivel em: https://www. feevale.br/Comum/midias/b8f7d75d-202c-48ab-9330-6b941321df51/E-BOOK\%20Cidades\%20Criativas.pdf. Acesso em: 19 fev. 2019.

BAIN, J. S. Barriers to New Competition. Cambridge, Mass.: Harvard UP, 1956

BENDASSOLLI, P. F; WOOD JR, T. KIRSCHBAUM, C; CUNHA, M. P. Indústrias Criativas no Brasil. Rio de Janeiro: FGV, 2009. p. 62-121.

BURGOON, J. K. The Challenge of Writing the Theoretical Essay. In: ALEXANDER, A.; POTTER, W. J (eds.) How to Publish Your Communication Research. London: Sage, 2001. p. 47-56.

BRITISH COUNCIL. Mapping the creative industries: the UK context. London, 2005.

CAVES, R. Creative Industries. Cambridge, Mass: Harvard: Harvard University Press,2000.

CHESNAIS, F. A Mundialização do Capital. Paris: Syro, 1994.

DRUCKER, P. Sociedade pós-capitalista. São Paulo: Thomson Pioneira, 2002.

EMMENDOERFER, M. L., FIORAVANTE, A. S. A., ARAÚJO, J. F. F. E. Federal government actions for the creative territories development in Brazilian context. Revista Brasileira de Gestão e Desenvolvimento Regional, v. 14, n.1, p. 400-424, 2018. 
FLORIDA, R. A Ascensão da classe Criativa. Porto Alegre: L\&PM, 2011.

GIL, A.C. Metodologia da Pesquisa Científica. São Paulo: Atlas, 2004.

HARTLEY, J. Creative Industries. London: Blackwell, 2005.

HIRSCHMAN, A. O. Estratégia do desenvolvimento econômico. Rio de Janeiro: Fundo de Cultura, 1961.

HOWKINS, J. The Creative Economy: How People Make Money From Ideas. London: Allen Lane, 2001.

MASON, E. S. Price production policies of large-scale enterprise. American Economic Review, v. 29, n.1, Mar. 1939.

NEF. Creative Europe Bonn: Network of European Foundations for Innovative Cooperation, 2002.

POSSAS, M. S. Notas acerca da lógica de decisão da firma capitalista. Campinas: Unicamp. Instituto de Economia, 1995.

Conhecimento e atividade econômica. Economia e Sociedade, v.8, p. 85-100, jun. 1997.

PRAHALAD, C., HAMEL, G. A competência essencial da corporação. In: MONTGOMERY, C. A., PORTER, M. E. Estratégia: a busca da vantagem competitiva. Rio de Janeiro: Campus, 1998. P. 293-316.

REIS, A. C. F. Economia criativa como estratégia de desenvolvimento: uma visão dos países em desenvolvimento. In Ana Carla Fonseca Reis (Org.). São Paulo: Itaú Cultural, 2008. p. 15 - 49.

ROODHOUSE, S. Defining the creative industries. Creative Industries Journal. v.1, n. 2, p. 137-150. Disponivel em: http://interjunction.org/article/defining-the-creative-industries/ Acesso em: 20.02.2019.

SILVA, A.L.G. Concorrência sob Condições Oligopolísticas. Campinas-SP: Unicamp, 2004.

SYLOS-LABINI, P. Oligopólio e Progresso Técnico. São Paulo: FORENSE/EDUSP, 1956.

TIGRE, P. B. (2005). Paradigmas tecnológicos e teorias econômicas da firma. Revista Brasileira de Inovação. v. 4, n 1, jan./jul. p. 187-224.

THE CREATIVE INDUSTRIES TASK FORCE. Report of the NBEDC Creative Economy Task Force. 2008. Disponivel em: http://nbedc.org/wp-content/uploads/creative-economy.pdf Acesso em: 16.12.2018

UNCTAD - United Nation Conference on Trade and Development. Creative Economy Report 2010: A Feasible Development Option. Disponivel em: http://www.unctad.org/Templates/webflyer.asp?docid=9750\&intltemID=4494\&lang=1\&mode=downloads. Acesso em: 01.03.2019. 
UNESCO. United Nations Educational, Scientific and Cultural Organizational. Evaluation Handbook: Internal Oversight Service Evaluation Section, 2006.

VERGARA, S. C. Sugestão para estruturação de um projeto de pesquisa. São Paulo: Atlas, 2005. 